\title{
Pseudocercospora actinidiae causes sooty spot disease on kiwifruit in Santa Catarina, Brazil
}

\author{
Leonardo Araujo ${ }^{1}$ (i) $\cdot$ Felipe Augusto Moretti Ferreira Pinto ${ }^{1}$ (i) $\cdot$ Camila Cristina Lage de Andrade ${ }^{2}$ (I) \\ Larissa Bitencourt Gomes ${ }^{2}\left(\right.$ Tatiana Mituti $^{2}\left(\right.$ Talmir Duarte $^{2}$. Val
}

Received: 10 March 2021 / Accepted: 4 August 2021 / Published online: 15 August 2021

(c) Australasian Plant Pathology Society Inc. 2021

\begin{abstract}
Sooty spot disease in kiwifruit is caused by Pseudocercospora actinidiae and is being reported here for the first time in Brazil. Morphological and molecular observations were consistent with those previously reported for $P$. actinidiae that have been associated with sooty spot disease on kiwifruit. To the best of our knowledge, this is the first report of $P$. actinidiae causing sooty spot disease on kiwifruit outside of the Asian continent.
\end{abstract}

Keywords Actinidia chinensis $\cdot$ Actinidia deliciosa $\cdot$ Leptosphaeria sp. · Black spot · Diseases kiwifruit

The sooty spot disease of kiwifruit, which is caused by Pseudocercospora actinidiae is of great concern to the Asian continent because of its difficulty to control and its potential to cause economic losses. The development of the disease causes symptoms in the leaves and fruit of kiwifruit vines (Actinidia chinensis and Actinidia deliciosa) (Kikuara and Nakashima 2008; Huang 2016; KVA 2020). Under high disease incidence in orchards and under favorable conditions, sooty spot can produce early defoliation (weakening vines and reducing yield) and fruit abscission (Huang 2016).

In Brazil, about 60 kiwifruit vines (Actinidia deliciosa) of the cultivar Hayward showing sooty spot symptoms were observed in a commercial orchard (established during the winter of 2018), during the summer of 2019 (Fig. 1A-C). Yellowish leaf spots and necrosis were observed on the adaxial surface (Fig. 1C). On the abaxial leaf surface, the first symptoms were small, dark spots (Fig. 1A and B). Later, these expanded and coalesced until dark spots with intense conidial masses were present in all leaves (Fig. 1A and B). Symptoms on the fruit were not observed until the harvest, although almost there was not fruit on kiwifruit vines. (Data not shown). Thus, the objective of the present study was to

Leonardo Araujo

leonardoaraujo@epagri.sc.gov.br

1 Empresa de Pesquisa Agropecuária e Extensão Rural de Santa Catarina (EPAGRI), Santa Catarina, Brazil

2 Agronômica Laboratório de Diagnóstico Fitossanitário e Consultoria, Porto Alegre, RS, Brazil confirm that $P$. actinidiae is the causal agent of the symptoms observed in kiwifruit vines in Brazil.

Leaves from symptomatic A. deliciosa cv. Hayward vines were collected from a commercial orchard in Bom Retiro, Santa Catarina (27 $\left.45^{\prime} 51^{\prime \prime S}, 49^{\circ} 43^{\prime} 44^{\prime \prime} \mathrm{W}\right)$, Brazil. To obtain a pure isolate, leaf spots containing fungal structures (Fig. 1A and B) were examined under a stereomicroscope (Leica EZ4E, Germany) fitted with a digital camera (5.0 Megapixel resolution). Conidia were dissected under a microscope and placed on a glass slide in a drop of sterile water, according to Park et al. (2017). After four days, the germinated conidia were transferred to Petri dishes containing potato dextrose agar (PDA). PDA plates were incubated at $25^{\circ} \mathrm{C}$ with photoperiod of $12 \mathrm{~h}$ for 15 days to develop colonies. The fungal isolates was preserved and deposited in the Micological Collection of the "Santa Verônica Giuliani" in Porto Alegre, RS, under registration number SVG00078F. Pathogenicity tests on kiwifruit leaves and fruit from $A$. deliciosa $\mathrm{cv}$. Hayward were performed according to Kikuara and Nakashima (2008).

Pseudocercospora actinidiae was confirmed by characterizing the length and width of the conidia (Kikuara and Nakashima 2008; Braun et al. 2015). Morphological observations were made under a BX41 microscope (Olympus, Japan), and images of the conidia were acquired digitally (Q-Color ${ }^{\mathrm{TM}}$, 5.0 Megapixel resolution) and further processed with Olympus cellSens Dimension software.

Mycelial disks from isolate were transferred into the malt extract broth $\left(20 \mathrm{~g} \mathrm{~L}^{-1}\right.$, Difco) by aseptically punching $5 \mathrm{~mm}$ 

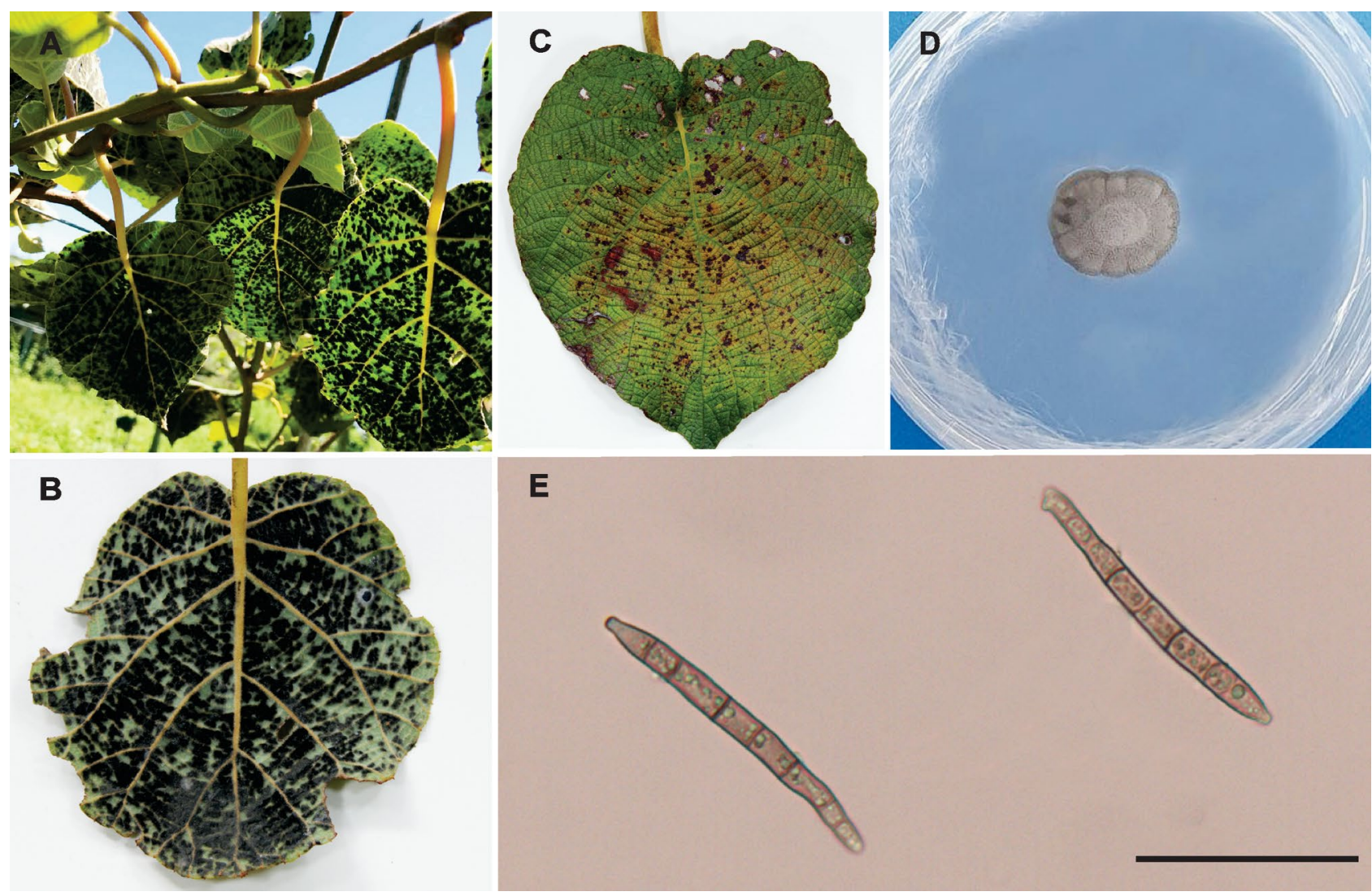

Fig. 1 Symptoms of sooty spot disease which is caused by Pseudocercospora actinidiae in the leaves of kiwifruit vines of the Actinidia deliciosa cv. Hayward. Disease symptoms on the abaxial leaves were small or coalesced, dark spots (A to $\mathbf{B})$. Yellowish leaf spots and necrosis were observed on the adaxial surface $(\mathbf{C})$. Fifty-days-old colonies of $P$. actinidiae growing on a potato dextrose agar dishes (D). Conidia of $P$. actinidiae (E). Bar: $50 \mu \mathrm{m}(\mathbf{C})$. Photos: J. O. Vieira (A) and L. Araujo (B to $\mathbf{E})$ disks of the agar plate culture. A shake flask culture was carried out in $250 \mathrm{~mL}$ flasks containing $50 \mathrm{~mL}$ of the medium at $110 \mathrm{rpm}$ and incubated at $25^{\circ} \mathrm{C}$ for four days. The mycelial growth was filtered, and the mycelial pellet was repeatedly washed with distilled water before being stored at $-20{ }^{\circ} \mathrm{C}$. For DNA extraction, the harvested fungal material was ground to a fine powder, in liquid $\mathrm{N}_{2}$ using a frozen pestle and mortar. Total DNA extraction using $100 \mathrm{mg}$ of homogenized ground material was performed using the Wizard Genomic DNA Purification Kit (Promega, Madison, USA). DNA integrity and concentration were assessed using a NanoDrop $^{\mathrm{TM}}$ spectrophotometer (ND-1000; Thermo Scientific, New Hampshire, USA). The DNA was stored at $-20{ }^{\circ} \mathrm{C}$ until the analysis was performed.

The molecular identity of the fungal isolate was determined using PCR amplification and sequencing of the internal transcribed spacer regions (ITS) according to White et al. (1990). The ITS primers used were ITS-1 and ITS-4. The PCR amplification program consisted of $94{ }^{\circ} \mathrm{C}$ for $2 \mathrm{~min}$, followed by 35 cycles of $94{ }^{\circ} \mathrm{C}$ for $30 \mathrm{~s}$, $54{ }^{\circ} \mathrm{C}$ for $30 \mathrm{~s}$ and $72{ }^{\circ} \mathrm{C}$ for $1 \mathrm{~min}$, with a final extension of $72{ }^{\circ} \mathrm{C}$ for $10 \mathrm{~min}$. The sequences obtained were edited using the BioEdit 7.0.5.3 software, and consensus sequences were analyzed using the Molecular Evolutionary Genetics Analysis (MEGA X) software (Kumar et al. 2018). The similarity of the nucleotide sequences of the isolate was calculated using the BLAST algorithm (Basic Local Alignment Search Tool). Sequences from reference strains of Pseudocercospora spp. (Silva et al. 2016) available in GenBank were added to the analyses. Cercospora eucalypti (CBS 11,318) was selected as an outgroup taxon. The Bayesian phylogenetic phylogenetic tree was reconstructed using the ITS data. The best nucleotide substitution models $(\mathrm{SYM}+\mathrm{G})$ for ITS were determined using the MrModeltest software (Posada and Buckley 2004). The CIPRES web portal (Miller et al. 2010) was used to run MrBayes v3.2.1 (Ronquist and Huelsenbeck 2003). The Markov Chain Monte Carlo (MCMC) analysis was run with a total of 10 million generations, sampling every 1,000 generations. The first $25 \%$ of the sampled vines were discarded as burn-in, and the posterior probability values were calculated using the remaining trees (Rannala and Yang 1996). The phylogenetic tree was visualized using the FigTree software (http://tree.bio.ed.ac.uk/software/ 


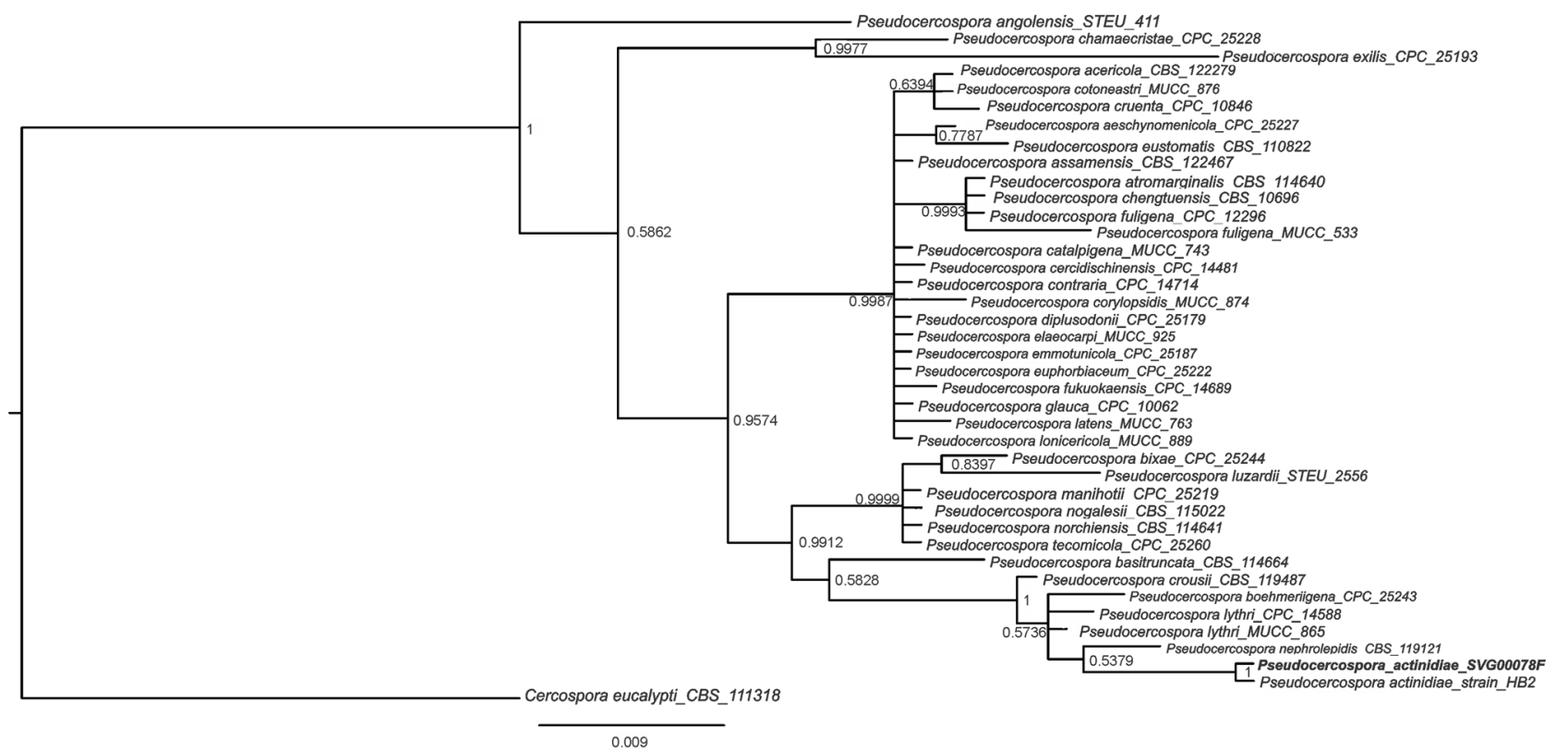

Fig. 2 The Bayesian phylogenetic tree based on ITS sequence of Pseudocercospora spp. The Bayesian posterior probabilities values are indicated above the nodes, and the scale bar represents the

figtree/). Sequences generated in this study were deposited in GenBank.

After 15 days of incubation, fungal colonies were darker, with smooth, lobate margins and erumpent with moderate aerial mycelia was observed. The surface appearance was pale olivaceous-gray and reverse iron gray (Fig. 1D). Conidiophores were not observed in fungal colonies developed on PDA plates. Koch's postulates were fulfilled with the kiwifruit leaves and fruit. The first symptoms in leaves were small and dark spots on the abaxial surface at 50 days after inoculation (dai). In fruit internal necrosis tissue in wound fruit were observed at 90 dai. Conidia were solitary, pale olivaceous brown, broadly obclavate-subcylindrical, 37.4-79.8 $(\overline{\mathrm{x}}=57.4)$ $\mu \mathrm{m} \times 5.3-8.3(\overline{\mathrm{x}}=7.0) \mu \mathrm{m}$, with a base $1.98-2.58(\overline{\mathrm{x}}=2.2)$ $\mu \mathrm{m}$ wide and $6-8$ sepate $(\overline{\mathrm{x}}=6.8)(\mathrm{n}=30)($ Fig. 1E). The Pseudocercospora isolate SVG00078-F was identical to P. actinidiae (accession number MK927158.1) (Fig. 2). The sequence was deposited in GenBank under accession number MT679154. The classification of Pseudocercospora species is based on a combination of morphological characteristics, host specificity, and molecular analyses (Stewart et al. 1999; Tang et al. 2009). According to the key of Pseudocercospora species in the Actinidiaceae the fungus $P$. actinidiae shows conidia broadly obclavatesubcylindrical, $25-85 \mu \mathrm{m} \times 5-8.5 \mu \mathrm{m}$, with a base that is 2-2.5 $\mu \mathrm{m}$ wide (Braun et al. 2015). Similarly Kikuara and Nakashima (2008) observed that conidia were pale olivaceous brown, obclavate to cylindrical, with unthickened, number of expected changes per site. The reference specimen CBS 111,138 of Cercospora eucalypti was used as outgroup

and truncate or obconically truncate basal ends, obtuse tips, 41-78 $\mu \mathrm{m} \times 4.3-5.8 \mu \mathrm{m}, 6-8$ sepate. Molecular techniques are commonly used to overcome taxonomic problems posed by the limitations of morphological analysis or in cases where morphological characteristics are in conflict, ambiguous, or missing (Tang et al. 2009; Park et al. 2017). Thus, in the present study, morphological and molecular observations indicate that $P$. actinidiae is the causal agent of the symptoms observed in kiwifruit vines in Brazil.

To our knowledge, this is the first report of $P$. actinidiae causing sooty spot disease in kiwifruit outside of the Asian continent. Little is known about the behavior of $P$. actinidiae in the Brazilian climate and additional studies are required to understand the potential economic impacts of this pathogen.

Acknowledgements Leonardo Araujo thanks CNPq for his fellowship. The authors thanks Arthur Oliveira Souza, Charles Aroldo Grudtner, Iran Souza Oliveira and James Oscar Vieira for their technical support and assistance.

Author contributions All authors contributed to the study conception and design. Material collection, obtaining images and pathogenicity test was performed by Leonardo Araujo and Felipe Augusto Moretti Ferreira Pinto. Morphological characteristics and molecular tests were performed by Camila Cristina Lage de Andrade, Larissa Bitencourt Gomes, Tatiana Mituti and Valmir Duarte. The first draft of the manuscript was written by L. Araujo and all authors commented on previous versions of the manuscript. All authors read and approved the final manuscript. 


\section{Declarations}

Informed consent Informed consent was obtained from all individual participants included in the study.

Conflict of interest Leonardo Araujo declares that he has no conflict of interest. Felipe Augusto Moretti Ferreira Pinto declares that he has no conflict of interest. Camila Cristina Lage de Andrade declares that she has no conflict of interest. Larissa Bitencourt Gomes declares that she has no conflict of interest. Larissa Bitencourt Gomes declares that she has no conflict of interest. Tatiana Mituti declares that she has no conflict of interest. Valmir Duarte declares that he has no conflict of interest. Ethical approval: This article does not contain any studies with human participants or animals performed by any of the authors.

\section{References}

Braun U, Crous PW, Nakashima C (2015) Cercosporoid fungi (Mycosphaerellaceae) 4. Species on dicots (Acanthaceae to Amaranthaceae). IMA Fungus 6(2):373-469

Huang H (2016) Pest, diseases and control. In H. Huang (ed), Kiwifruit: The Genus Actinidia (1rd ed. Academic Press, pp. 280-292). London

Kikuhara K, Nakashima C (2008) Sooty Spot of kiwifruit caused by Pseudocercospora actinidiae Deighton. J Gen Plant Pathol 74(2):185-187

Kumar S, Stecher G, Li M, Knyaz C, Tamura K (2018) Mol Biol Evol 35:1547-1549

KVH - Kiwifruit Vine Heath (2020) Kiwifruit risk organisms. Retrieved February, 23, 2021 from http://www.kvh.org.nz/vdb/ document/91544
Miller MA, Pfeiffer W, Schwartz T (2010) Creating the CIPRES Science Gateway for inference of large phylogenetic trees. In Proceedings of the Gateway Computing Environments Workshop (GCE), 14 Nov. 2010, New Orleans, LA, 1-8

Park SH, Choi IY, Seo KW, Kim JH, Galea V, Shin HD (2017) Identification and characterization of Pseudocercospora pyricola causing leaf spots on Aronia melanocarpa. Mycobiology 45(1):39-43

Posada D, Buckley TR (2004) Model selection and model averaging in phylogenetics: advantages of akaike information criterion and bayesian approaches over likelihood ratio tests. Syst Biol 53(5):793-808

Rannala B, Yang Z (1996) Probability distribution of molecular evolutionary trees: A new method of phylogenetic inference. J Mol Evol 43(3):304-311

Ronquist F, Huelsenbeck JP (2003) MrBayes 3: bayesian phylogenetic inference under mixed models. Bioinformatics 19(12):1572-1574

Silva M, Barreto RW, Pereira OL, Freitas NM, Groenewald JZ, Crous PW (2016) Exploring fungal mega-diversity: Pseudocercospora from Brazil. Persoonia - Molecular Phylogeny and Evolution of Fungi 37(1):142-172

Stewart EL, Liu Z, Crous PW, Szabo LJ (1999) Phylogenetic relationships among some cercosporoid anamorphs of Mycosphaerella based on rDNA sequence analysis. Mycol Res 103(11):1491-1499

Tang AM, Jeewon R, Hyde KD (2009) A re-evaluation of the evolutionary relationships within the Xylariaceae based on ribosomal and protein-coding gene sequences. Fungal Diversity 34(1):127-155

White TJ, Bruns TD, Lee SB, Taylor JW (1990) Amplification and Direct Sequencing of Fungal Ribosomal RNA Genes for Phylogenetics. In: M. A. Innis, D. H. Gelfand, J. J. Sninsky, T. J. White (eds) PCR Protocols: A Guide to Methods and Applications. (1rd ed. Academic Press, pp. 315-322). New York 